\title{
Aspectos clínico-patológicos e imuno-histoquímicos de equídeos infectados pelo vírus da raiva ${ }^{1}$
}

\author{
Pedro M.O. Pedroso², Edson M. Colodel ${ }^{3}$, Danilo C. Gomes², Mary S. \\ Varaschin ${ }^{4}$, Pedro S. Bezerra Júnior ${ }^{4}$, José D. Barbosa ${ }^{5}$, Carlos H. \\ Tokarnia $^{6}$ e David Driemeier ${ }^{2^{*}}$
}

\begin{abstract}
Pedroso P.M.O., Colodel E.M., Gomes D.C., Varaschin M.S., Bezerra Júnior P.S., Barbosa J.D., Tokarnia C.H. \& Driemeier D. 2010. [Clinic-pathological and immunohistochemical aspects of equids infected with rabies virus.] Aspectos clínicopatológicos e imuno-histoquímicos de equídeos infectados pelo vírus da raiva. Pesquisa Veterinária Brasileira 30(11):909-914. Setor de Patologia Veterinária, Faculdade de Veterinária, Universidade Federal do Rio Grande do Sul, Av. Bento Gonçalves 9090, Porto Alegre, RS 91540-000, Brazil. E-mail: davetpat@ufrgs.br

Thirteen horses and one mule from four regions of Brazil with clinical and histological diagnosis of rabies were analyzed. The clinical course lasted four days, with motor incoordination, paresis and paralysis of the legs, and decubitus. The main histopathological findings were lymphoplasmacytic meningoencephalitis and non-suppurative meningomyelitis associated with characteristic Negri bodies in $64.28 \%(9 / 14)$ cases, mainly in the cervical spinal cord and in Purkinje neurons of the cerebellum. In 55.55\% (5/9), the animals examined were positive by for the fluorescent antibody test for rabies. All animals were positive in immunohistochemistry for rabies, whose immunolabeling were more evident in the temporal cortex, occipital cortex and cervical spinal cord. Immunohistochemistry procedure was essential to confirm all cases of rabies in the equids.
\end{abstract}

INDEX TERMS: Rabies, Lyssavirus, equids, immunohistochemistry.

RESUMO.- Foram analisados 14 equídeos (13 equinos e 1 muar) com diagnóstico clínico e histológico de raiva provenientes de quatro regiões do Brasil. O curso clínico médio foi de quatro dias de evolução, incluindo incoordenação

\footnotetext{
${ }^{1}$ Recebido em 12 de julho de 2010.

Aceito para publicação em 21 de julho de 2010.

Parte da dissertação de mestrado do primeiro autor, Programa de Pós-graduação em Ciências Veterinárias, Universidade Federal do Rio Grande do Sul (UFRGS), Av. Bento Gonçalves 9090, Porto Alegre, RS 95320-000, Brasil.

2 Setor de Patologia Veterinária (SPV), Departamento de Patologia Clínica Veterinária, Faculdade de Veterinária, UFRGS, Av. Bento Gonçalves 9090, Porto Alegre, RS 91540-000. *Autor para correspondência: davetpat@ufrgs.br

${ }^{3}$ Departamento de Clínica Médica Veterinária, Faculdade de Agronomia e Medicina Veterinária, Universidade Federal de Mato Grosso (UFMS), Av. Fernando Correia da Costa s/n, Bairro Coxipó, Cuiabá, MT 78068-900, Brasil.

${ }^{4}$ Setor de Patologia Veterinária, Universidade Federal de Lavras (UFLA), Lavras, MG 37200-000, Brasil.

${ }^{5}$ Central de Diagnóstico Veterinário (Cedivet), Universidade Federal do Pará (UFPA), Castanhal, PA 68743-080, Brasil.

${ }^{6}$ Departamento de Nutrição Animal e Pastagem, Universidade Federal Rural do Rio de Janeiro (UFRRJ), Seropédica, RJ 23890-000, Brasil.
}

motora, paralisia dos membros pélvicos, paresia dos membros torácicos e decúbito. Os achados histopatológicos caracterizaram-se por meningoencefalite e meningomielite não supurativa com infiltrado perivascular linfoplasmocitário. Corpúsculos de Negri foram observados em 64,28\% (9/14) dos casos, principalmente na medula espinhal cervical e nos neurônios de Purkinje do cerebelo. Em 55,55\% (5/9) dos equídeos analisados tiveram resultado positivo pela técnica de imunofluorescência direta para raiva. Todos os casos foram positivos na imuno-histoquímica para raiva, cujas reações foram mais evidentes no córtex temporal, córtex occipital e medula espinhal cervical. A técnica de imuno-histoquímica foi essencial para confirmar todos os casos de raiva nos equídeos.

TERMOS DE INDEXAÇÃO: Raiva, Lyssavirus, equídeos, imuno-histoquímica.

\section{INTRODUÇÃO}

A raiva é uma encefalite altamente fatal causada por um vírus RNA do gênero Lyssavirus, distribuída em quase todo o mundo (Lima et al. 2005, Pierezan et al. 2007). Na América do Sul a raiva é transmitida por morcegos 
hematófagos; bovinos e equinos são as espécies mais afetadas (Peixoto et al. 2000, Radostits et al. 2002). Em equinos o quadro clínico é semelhante ao de bovinos, caracterizado por depressão, incoordenação motora, paralisia dos membros pélvicos e torácicos, decúbito lateral, paralisia faríngea, cegueira, depressão, agressividade, galope desenfreado e ataxia são frequentes (Green et al. 1992, Radostits et al. 2002, Lima et al. 2005, Pierezan et al. 2007). Em estudo de doenças de equídeos no Nordeste brasileiro, de 159 casos analisados, 49 (30,8\%) estavam relacionados a enfermidades do sistema nervoso central. A raiva foi a terceira em número de casos diagnosticados, representando $24,4 \%$, sendo a doença viral em equídeos mais importante na região (Pimentel et al. 2009).

Por se tratar de uma doença pouco estudada em equídeos, o objetivo do presente trabalho foi descrever os achados clínico-patológicos e imuno-histoquímicos de casos naturais de raiva em 14 equídeos de diferentes regiões geográficas do Brasil.

\section{MATERIAL E MÉTODOS}

Foram avaliadas amostras de sistema nervoso central (SNC) de treze equinos e uma amostra de um muar, todos com descrição histológica de meningoencefalite e meningomielite não supurativa, em cinco casos já confirmados pela imunofluorescência direta (IFD) para raiva. Os equinos foram numerados de 1 a 13 e o muar como número 14 . Cinco amostras de equinos vieram do Laboratório de Patologia Veterinária da Universidade Federal de Mato Grosso (LPVUFMT) (Equinos 1, 2, 3, 4 e 5), duas do Setor de Patologia Veterinária da Universidade Federal do Rio Grande do Sul (SPV-UFRGS) (Equinos 6 e 7), cinco amostras da Central de Diagnóstico Veterinário da Universidade Federal do Pará (Cedivet-UFPA) (Equinos 8, 9, 10, 11, 12) e duas do Setor de Patologia Veterinária da Universidade Federal de Lavras (SPVUFLA) (Equino 13 e Muar 14). Todas as amostras vieram acompanhadas de histórico, sinais clínicos, raça, idade e sexo dos animais afetados.

Os animais foram necropsiados e fragmentos de diversos órgãos foram fixados em formol $10 \%$, processados pelos métodos histológicos de rotina e coradas pela hematoxilina e eosina (HE). De todos os animais, cortes seriados de medula espinhal cervical $(\mathrm{MC})$, bulbo à altura do óbex $(\mathrm{BO})$, ponte à altura dos pedúnculos cerebelares $(\mathrm{PO})$, mesencéfalo à altura dos colículos rostrais (ME), tálamo (TA), cerebelo (CE), córtex frontal $(\mathrm{CF})$, córtex parietal $(\mathrm{CP})$, córtex temporal $(\mathrm{CT})$, córtex occipital $(\mathrm{CO})$ e hipocampo $(\mathrm{HC})$ foram submetidos à técnica de imuno-histoquímica (IHQ) para raiva, previamente descrita (Pedroso et al. 2008a). Como anticorpo primário foi utilizado o anticorpo primário policlonal (Rabies Polyclonal DFA, Chemicon \#5199, Temecula, CA, Estados Unidos, adaptado de Rech 2007) na diluição de 1:1000 em PBS (phosphate buffered saline) e revelado com o cromógeno vermelho (VECTOR ${ }^{\circledR}$ NovaRED, Vector Laboratories, Burlingame, CA, Estados Unidos). Como controle positivo foi utilizado um corte histológico de SNC de um bovino acometido por raiva e com resultado positivo nas provas de IFD, inoculação intracerebral em camundongo (ICC) e IHQ (Pedroso et al. 2008a). Todas as amostras utilizadas tiveram resultado negativo para herpesvírus equino tipo 1 pela técnica de $\mathrm{IHQ}$.

\section{RESULTADOS}

A idade média dos equinos foi quatro anos e variou de 70 dias até 15 anos. Um equino era da raça Pantaneiro, um da raça Crioula, um da raça Quarto de Milha, um da raça Manga Larga Marchador, quatro sem raça definida (SRD);

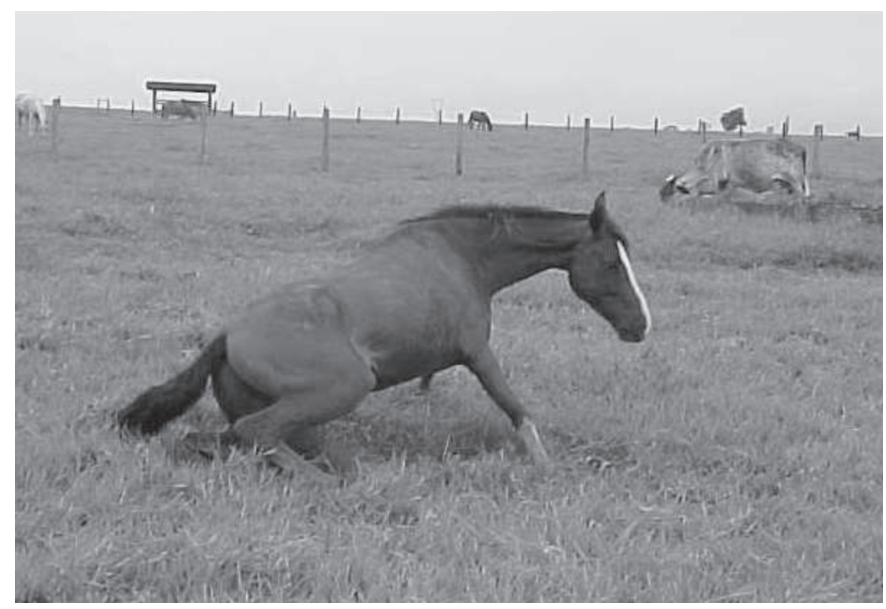

Fig.1. Equino $11 \mathrm{com}$ paralisia dos membros pélvicos.

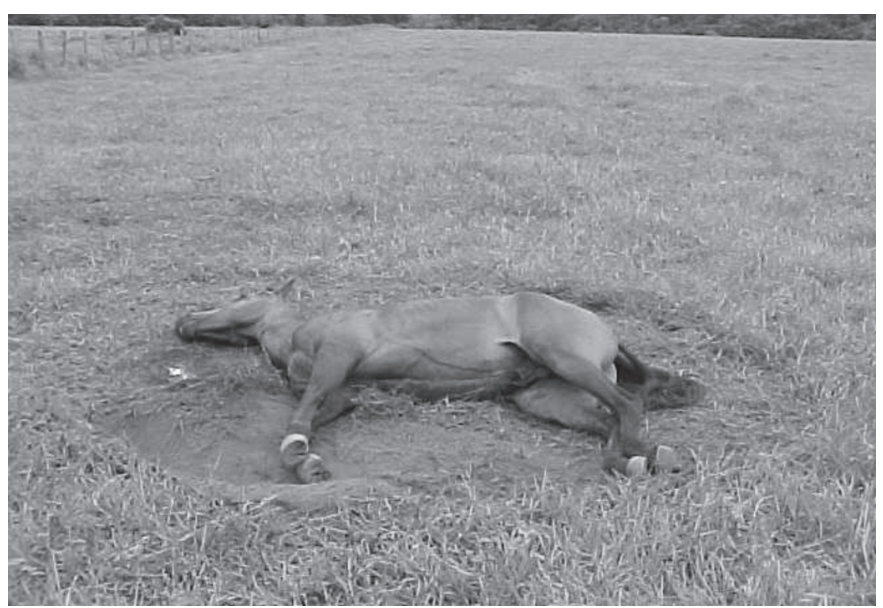

Fig.2. Equino 10 em decúbito lateral direito e com movimentos de pedalagem.

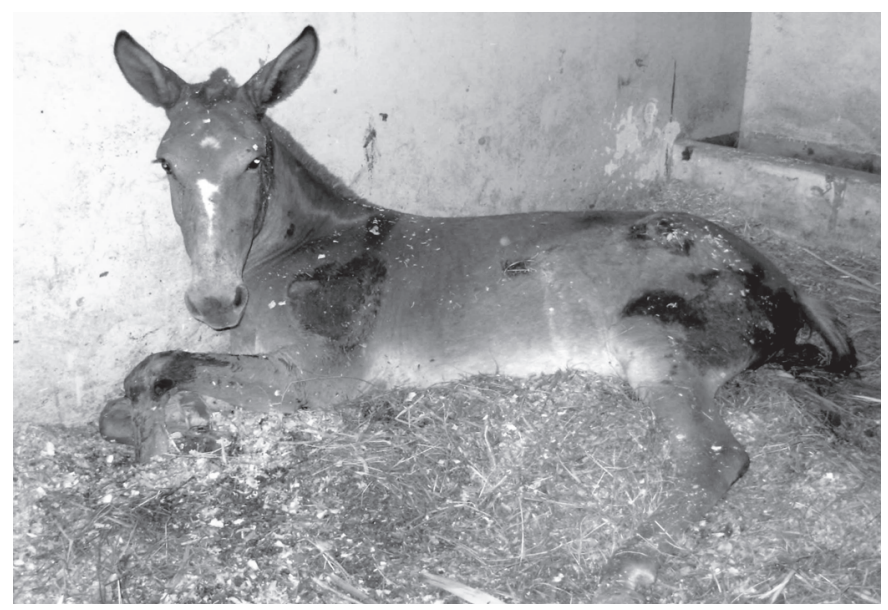

Fig.3. Muar em decúbito lateral direito, com paralisia dos membros pélvicos e com escaras de decúbito. 
em cinco casos a raça não foi informada pelo requisitante. Oito animais eram machos e cinco eram fêmeas. A média de evolução do quadro clínico foi 3,6 dias. Sete equinos tiveram morte natural (Equinos 2, 4, 5, 6, 9, 10 e 13) e seis foram eutanasiados (Equinos 1, 3, 7, 8, 11 e 12). A forma clínica dos animais acometidos foi a paralítica (13/13). 0 muar era uma fêmea proveniente da região de Nazareno/ Minas Gerais, sem idade informada e foi acometido pela forma paralítica com quatro dias de evolução clínica.

Os principais sinais clínicos nos equinos caracterizaram-se por incoordenação motora (13/13), paralisia dos membros pélvicos (12/13) (Fig.1), decúbito lateral (12/13), paresia dos membros torácicos $(8 / 13)$, movimentos de pedalagem (2/13) (Fig.2), paralisia da cauda (1/13), diminuição do tônus lingual (1/13) e depressão (1/13). Na propriedade do equino 1 já haviam morrido desde o ano de 2006 aproximadamente doze equinos com sinais clínicos similares a este animal. Os Equinos 2 e 13 tinham sido vacinados para raiva há quatro e vinte dias antes de adoecerem, respectivamente. Na propriedade do Equino 8, de
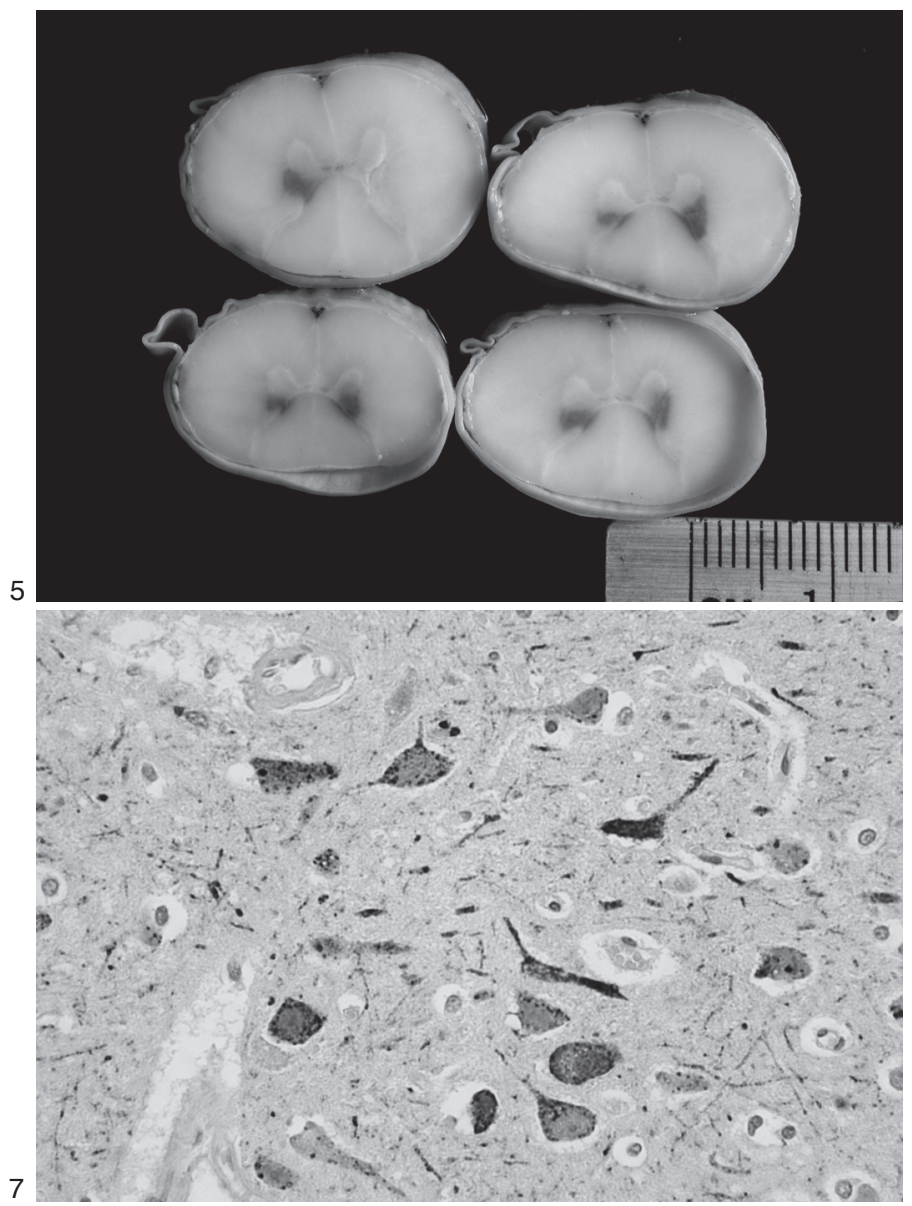

Fig.5. Áreas de hemorragia na substância cinzenta da medula espinhal cervical fixada em formol 10\% (Equino 7).

Fig.7. Imunomarcação acentuada do antígeno da raiva na região do córtex occipital (Equino 4). Método biotina-estreptavidina-peroxidase e contra-corado com hematoxilina, obj.20x.

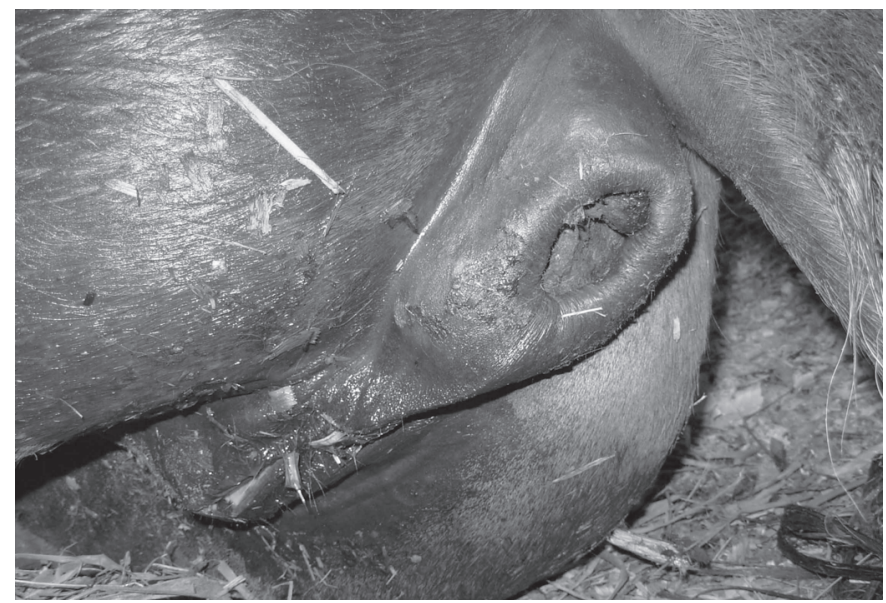

Fig.4. Muar com falta de tônus do esfíncter anal.

um total de doze animais, seis (dois asininos e quatro equinos) haviam morrido. Os equinos arrastavam os membros pélvicos e em seguida evoluía para os membros

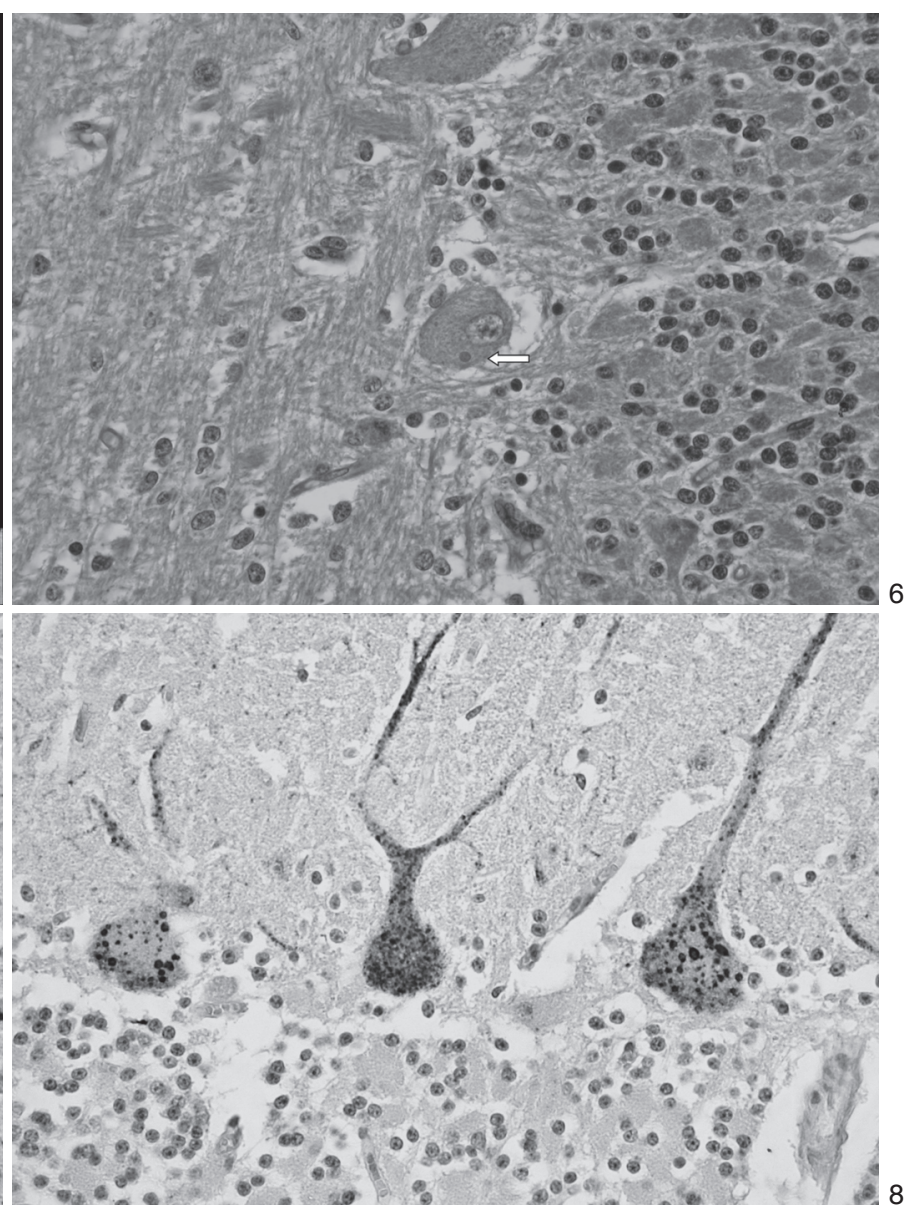

Fig.6. Corpúsculo de Negri (seta) em neurônio de Purkinje do cerebelo (Equino 11). HE, obj.40x.

Fig.8. Imunomarcação do antígeno da raiva na forma de agregados de grânulos em neurônios de Purkinje do cerebelo (Equino 4). Método biotina-estreptavidina-peroxidase e contra-corado com hematoxilina, obj.40x. 
torácicos. Nos Equinos 10, 11 e 12 a suspeita inicial era de Herpesvírus equino (EHV). O muar foi o segundo animal a adoecer na propriedade, sendo que o primeiro teve resultado negativo para raiva por IFD. O muar apresentou um quadro clínico caracterizado por decúbito lateral (Fig.3), movimentos de pedalagem, paralisia flácida dos membros pélvicos e da cauda, falta de tônus do esfíncter anal (Fig.4), com quatro dias de evolução clínica. Um dado bastante interessante é que continuou a ingerir água e comer até poucos instantes antes de morrer espontaneamente. À necropsia, três animais (Equinos 1, 6 e 7) apresentaram distensão da bexiga urinária. $O$ Equino 7 apresentou áreas de hemorragia acentuada na substância cinzenta da medula espinhal cervical (Fig.5) até a região da medula espinhal torácica. No muar somente havia escoriações nas regiões dos membros pélvicos e torácicos.

Os principais achados histopatológicos nos equídeos deste estudo caracterizaram-se por meningoencefalite e meningomielite não supurativa com infiltrado perivascular linfoplasmocitário, microgliose focal, neuronofagia e com raras inclusões intracitoplasmáticas (corpúsculos de Negri) (Fig.6); estas foram observados em 64,28\% (9/14) dos casos, principalmente na medula espinhal cervical e nos neurônios de Purkinje do cerebelo. Na histologia da medula espinhal cervical do equino 7 , observaram-se focos de inflamação não supurativa moderada, congestão moderada e focos de hemorragia na substância cinzenta. O exame de IFD para raiva das amostras de encéfalo e cerebelo dos Equinos 3, 5, 6 e 7 deram resultado negativo. Amostras de SNC dos Equinos 8, 9, 10, 11 e 12 não foram enviadas para realização de IFD para raiva por terem sido encaminhadas já fixado em formol. A prova de IFD somente confirmou a doença em 55,55\% (5/9) dos casos.

Todos os casos submetidos à técnica de imuno-histoquímica para raiva foram positivos. Houve imunomarcação para o antígeno da raiva em neurônios da medula espinhal cervical, nos núcleos do tronco encefálico, em neurônios de Purkinje do cerebelo e de seus processos na camada molecular e na camada profunda do córtex telencefálico. Os locais do SNC que tiveram marcação do antígeno rábico em todos os casos ocorreram no córtex temporal e córtex occipital (Fig.7). A melhor intensidade média de marcação imuno-histoquímica foi evidenciada em ordem decrescente no córtex temporal, córtex occipital e medula espinhal cervical. O Equino 3 somente apresentou imunomarcação leve de antígeno rábico na medula espinhal cervical, identificando-se agregados de antígenos no pericário. Nos casos analisados pode-se observar imunomarcação no pericário, axônios e dendritos de neurônios tanto na forma de agregados de grânulos de antígeno viral (Fig.8) como também na forma redonda ou oval. No Equino 7, se obteve melhor imunomarcação na medula espinhal cervical e mesencéfalo. O muar obteve melhor imunomarcação na região do mesencéfalo à altura dos colículos rostrais. Os resultados observados à $\mathrm{IHQ}$ dos cortes seriados do SNC estão apresentados no Quadro 1.
Quadro 1. Locais e intensidade de marcações imunohistoquímicas em cortes histológicos de SNC de equídeos naturalmente afetados pela raiva

\begin{tabular}{cccccccccccc}
\hline Equídeo & MC & BO & PO & ME & TA & CE & CF & CP & CT & CO & HC \\
\hline 1 & 1 & 2 & 3 & 3 & 2 & 1 & 3 & 3 & 3 & 1 & 3 \\
2 & 3 & 2 & 2 & 2 & NA & 3 & 0 & NA & NA & NA & NA \\
3 & 3 & 0 & 0 & 0 & NA & 0 & NA & 0 & NA & NA & 0 \\
4 & NA & 2 & 3 & NA & NA & 3 & 3 & 1 & 3 & 3 & 1 \\
5 & NA & NA & 0 & 0 & 1 & 1 & 1 & 2 & 2 & 3 & 0 \\
6 & 1 & NA & NA & NA & NA & 2 & NA & 2 & 2 & NA & NA \\
7 & 3 & NA & 2 & 3 & NA & 1 & NA & 0 & NA & NA & NA \\
8 & 2 & 0 & NA & NA & 0 & 0 & NA & 0 & NA & NA & NA \\
9 & 3 & NA & 1 & NA & 2 & 1 & NA & 1 & 1 & NA & NA \\
10 & 0 & NA & NA & NA & 2 & NA & NA & 1 & NA & NA & NA \\
11 & 2 & NA & NA & NA & NA & 1 & 2 & NA & NA & NA & NA \\
12 & NA & NA & 1 & NA & 1 & 1 & NA & NA & NA & 1 & 0 \\
13 & 3 & 3 & 2 & 1 & NA & NA & NA & NA & NA & NA & NA \\
14 & 1 & NA & 1 & 3 & NA & 0 & NA & NA & NA & NA & NA \\
IM & 2,0 & 1,5 & 1,5 & 1,71 & 1,33 & 1,16 & 1,8 & 1,11 & 2,2 & 2,0 & 0,8
\end{tabular}

$\mathrm{MC}=$ medula espinhal cervical, $\mathrm{BO}=$ bulbo na altura do óbex, $\mathrm{PO}=$ ponte com pedúnculos cerebelares, $\mathrm{ME}=$ mesencéfalo na altura dos colículos rostrais, $\mathrm{TA}=$ tálamo, $\mathrm{CE}=$ cerebelo, $\mathrm{CF}=$ córtex frontal, $\mathrm{CP}=$ córtex parietal, $\mathrm{CT}=$ córtex temporal, $\mathrm{CO}=$ córtex occipital, $\mathrm{HC}$ = hipocampo, 0 = ausência de marcação, 1 = marcação leve, 2 = marcação moderada, 3 = marcação acentuada, NA = secção do SNC não avaliada, IM = intensidade média de marcação imuno-histoquímica por região do SNC.

\section{DISCUSSÃO}

O diagnóstico de raiva dos equídeos foi baseado nos dados epidemiológicos, sinais clínicos, lesões histológicas, imunofluorescência direta e na técnica de imuno-histoquímica para raiva. As amostras analisadas deste estudo foram de quatro regiões geográficas do Brasil, todas relacionadas com histórico de mordedura do morcego hematófago Desmodus rotundus, o principal transmissor da raiva em herbívoros na América do Sul. Não houve predileção por raça, sexo e idade nos animais em estudo. Em equinos é muito variável o quadro clínico; sinais clínicos podem estar associados ao cérebro, tronco encefálico, cerebelo e medula espinhal (Lima et al. 2005). Os sinais clínicos dos equídeos analisados foram semelhantes aos descritos por outros autores (Pierezan et al. 2007, Pimentel et al. 2009). Todos equídeos deste estudo foram acometidos pela forma paralítica da doença. A raiva paralítica está associada a lesões da medula espinhal e tronco encefálico e é mais frequente em herbívoros (Fernandes \& Riet-Correa 2007). No Nordeste brasileiro foram observados três casos de raiva em equinos da forma cerebral, que apresentaram tanto agressividade quanto depressão profunda (Lima et al. 2005). Apesar de a raiva ser endêmica em várias regiões, a vacinação de equinos não é obrigatória. No caso dos Equinos 2 e 13 que tinham sido vacinados, é de se supor que estes animais já pudessem estar incubando o vírus da raiva ou mesmo de ter ocorrido falha na estimulação da resposta imune devido à variação individual (Tizard 1996, Langohr et al. 2003). A doença tem sido pouco estudada em equídeos no Brasil (Lima et al. 2005). É importante destacar que o baixo número de casos de raiva em equídeos 
pode estar também relacionado ao não envio de amostras de materiais provenientes de necropsias para exame confirmatório por parte do médico veterinário, pois muitas vezes este acaba dar um diagnóstico clínico em decorrência de experiências anteriores na qual havia mandado material. Em um estudo retrospectivo de casos de raiva no período de 1985-2007 realizado pelo Instituto de Pesquisas Veterinárias Desidério Finamor (IPVDF), Rio Grande do Sul, $656(88,7 \%)$ das amostras positivas, eram de origem bovina e somente 21 eram da espécie equina (2,9\%) (Teixeira et al. 2008). Em outro estudo realizado entre os anos de 1981 a 1994 no Estado de São Paulo, a raiva acometeu 983 bovinos e somente 111 equinos (Peixoto et al. 2000).

As alterações histológicas observadas no presente estudo, caracterizadas por meningoencefalite e meningomielite não supurativa com presença de corpúsculos de Negri, foram similares às descritas por outros autores (Lima et al. 2005, Maxie \& Youssef 2007, Pierezan et al. 2007). Áreas de hemorragia na medula espinhal do equino 7 foram semelhantes às observadas por O'Toole et al. (1993); porém nesse caso além de hemorragia foi encontrada poliomielomalacia. Em estudo comparativo das três técnicas de diagnóstico de raiva em bovinos e equinos, verificou-se que na espécie equina, somente em algumas oportunidades foi possível identificar corpúsculos de Negri pelo método histológico (Peixoto et al. 2000). No entanto, no presente estudo observou-se corpúsculos intracitoplasmáticos em $64,28 \%$ dos casos analisados Essa frequência foi maior que a observada por Grenn et al. (1992) com 47\%; por Lima et al. (2005) com 40\%; por Peixoto et al. (2000) com 36,9\%; e por Pierezan et al. (2007) que obteve $33,33 \%$, porém essa frequência é menor que a observada na espécie bovina (Rech 2007, Pedroso et al. 2009). No presente estudo, em $35,71 \%$ (5/14) equídeos não foram observados corpúsculos intracitoplasmáticos em neurônios, e está abaixo dos resultados obtidos dentro desta espécie (Green et al. 1992, Peixoto et al. 2000, Lima et al. 2005, Pierezan et al. 2007). A ausência de corpúsculos de inclusão pode estar relacionada com o estágio, curso da doença (Fernandes \& Riet-Correa 2007), sendo mais frequentemente observado quando os animais sobrevivem por quatro dias ou mais (Green et al. 1992) e pela cepa de vírus circulante, pois algumas não produzem corpúsculos de Negri (Jones et al. 2000, Lima et al. 2005).

O diagnóstico de raiva utilizando-se a técnica de IFD e IHQ fica na ordem de 98\% (Zimmer et al. 1990), porém nos casos aqui analisados a prova de IFD somente obteve resultado positivo em $55,55 \%$ e na ordem dos casos de $100 \%$ pela técnica de IHQ. Neste estudo mostrou-se quanto é importante a IHQ como ferramenta auxiliar no diagnóstico de raiva em equídeos, especialmente nos casos em que a IFD é negativa, e em casos onde o material é encaminhado em formol ao laboratório de diagnóstico. Os locais do SNC de melhor intensidade média de marcação imuno-histoquímica ocorreram no córtex temporal, córtex occipital e medula espinhal cervical. Já na espécie bovina os melhores locais de marcação e intensidade média foram no bulbo à altura do óbex, ponte e mesencéfalo à altura dos colículos rostrais (Pedroso et al. 2009). Nos Equinos 3, 5, 6 e 7 somente foi possível confirmar a doença pela imunomarcação positiva de neurônios na IHQ, pois na IFD o resultado havia sido negativo. No Mato Grosso do Sul, em um surto de raiva em equinos, um caso foi negativo nas provas de IFD e prova biológica e confirmado positivo na imuno-histoquímica (Pierezan et al. 2007). Nesta situação a IHQ pode ser uma importante ferramenta auxiliar no diagnóstico da raiva, pois nem sempre há uma concordância completa entre as provas (Zimmer et al. 1990). Em trabalho de Silva et al. (1974), somente foi confirmada a presença do vírus da raiva na medula espinhal e bulbo de equinos na doença natural e sua ausência nas diferentes regiões do sistema nervoso central e outros tecidos. A $\mathrm{IHQ}$ tem se revelado uma ferramenta auxiliar importante na rotina de laboratórios de diagnóstico veterinário, especialmente quando as amostras de SNC são submetidas ao laboratório já fixados em formol $10 \%$, o que impossibilita a realização de provas de IFD e ICC (Pedroso et al. 2008b), com vantagem de confirmar o diagnóstico de raiva como foi observado no caso do Equino 8. No Equino 3 somente se confirmou raiva através da marcação imunohistoquímica na medula espinhal. Deve-se, portanto assim realizar a colheita de todo o SNC, para que vários segmentos sejam analisados e estudados para auxiliar no diagnóstico final. É importante realizar o diagnóstico diferencial com outras encefalites como encefalomielite equina, herpesvírus equino, toxoplasmose, listeriose, leucoencefalomalácia (Peixoto et. al. 2000) e de plantas hepatotóxicas que causam encefalopatia hepática como Senecio spp. e Crotalaria spp. (Gava \& Barros 1997, Nobre et al. 2004, Fernandes \& Riet-Correa 2007); esta última é a principal causa de doenças do sistema nervoso de equídeos da Região Nordeste do Brasil (Pimentel et al. 2009).

Agradecimentos.- Os autores agradecem ao Instituto de Pesquisas Veterinárias Desidério Finamor (IPVDF-RS), ao Laboratório de Apoio a Saúde Animal do Instituto de Defesa Agropecuária do Estado de Mato Grosso (LASA-INDEA-MT) e ao Instituto Mineiro de Agropecuária (IMA) pelos resultados de IFD de raiva dos materiais encaminhados. Parte deste trabalho foi financiada pela Coordenação de Aperfeiçoamento de Pessoal de Nível Superior (CAPES) e pelo Conselho Nacional de Desenvolvimento Científico e Tecnológico (CNPq).

\section{REFERÊNCIAS}

Fernandes C.G. \& Riet-Correa F. 2007. Raiva, p.184-198. In: RietCorrea F., Schild A.L., Lemos R.A.A. \& Borges J.R.J. (Eds), Doenças de Ruminantes e Equídeos. Vol.1. $3^{\underline{a}}$ ed. Pallotti, Santa Maria.

Gava A. \& Barros C.S.L. 1997. Senecio spp. poisoning of horses in southern Brazil. Pesq. Vet. Bras. 17:36-40.

Green S.L., Smith L.L., Vernau W. \& Beacock S.M. 1992. Rabies in horses: 21 cases (1970-1990). J. Am. Vet. Med. Assoc. 200:11331137.

Jones T.C., Hunt R.D. \& King N.W. 2000. Patologia Veterinária. Manole, Barueri, p.335-339.

Maxie M.G., Youssef S. 2007. The nervous system, p.283-455. In: Maxie M.G. (Ed.), Jubb, Kennedy, and Palmer's Pathology of Domestic Animals. Vol.1. $5^{\text {th }}$ ed. W.B. Saunders, Philadelphia. 
Langohr I.M., Irigoyen L.F., Lemos R.A.A. \& Barros C.S.L. 2003. Aspectos epidemiológicos, clínicos e distribuição das lesões histológicas no encéfalo de bovinos com raiva. Ciência Rural 33:25131.

Lima E.F., Riet-Correa F., Castro R.S., Gomes A.A.B. \& Lima F.S. 2005. Sinais clínicos, distribuição das lesões no sistema nervoso e epidemiologia da raiva em herbívoros na região Nordeste do Brasil. Pesq. Vet. Bras. 25:250-264.

Nobre V.M.T., Riet-Correa F., Barbosa Filho J.M., Dantas A.F.M., Tabosa I.V. \& Vasconcelos J.S. 2004. Intoxicação por Crotalaria retusa (Fabaceae) em equídeos no semi-árido da Paraíba. Pesq. Vet. Bras. 24:132-143.

O'Toole D., Mills K., Ellis J., Welch V. \& Fillerup M. 1993. Poliomyelomalacia and ganglioneuritis in a horse with paralytic rabies. J. Vet. Diagn. Invest. 5:594-597.

Pedroso P.M.O., Pescador C.A., Bandarra P.M., Raymundo D.L., Borba M.R., Wouters F., Bezerra Júnior P.S. \& Driemeier D. 2008a. Padronização da técnica de imuno-histoquímica para raiva em amostras de sistema nervoso central de bovinos fixados em formol e emblocados em parafina. Pesq. Vet. Bras. 28:627-632.

Pedroso P.M.O., Dalto A.G.C., Borba M.R., Oliveira L.G.S., Costa G.R. \& Driemeier D. 2008b. Contribuição da imuno-histoquímica para o diagnóstico de raiva em bovinos do programa DXSNC-MAPA no Setor de Patologia Veterinária da UFRGS. Revta Univ. Rural., Ciênc. Vida 28:601-603.

Pedroso P.M.O., Colodel E.M., Pescador C.A., Arruda L.P. \& Driemeier D. 2009. Aspectos clínicos e patológicos em bovinos afetados por raiva com especial referência ao mapeamento do antígeno rábico por imuno-histoquímica. Pesq. Vet. Bras. 29:899-904.

Peixoto Z.M.P., Cunha E.M.S., Sacramento D.R.V., Souza M.C.A.M., Silva L.H.Q., Germano P.L., Kroeff S.S. \& Kotait I. 2000. Rabies laboratory diagnosis: Peculiar features of samples from equine origin. Braz. J. Microbiol. 31:72-75.

Pierezan F., Lemos R.A.A., Rech R.R., Rissi D.R., Kommers G.D., Cortada V.C.L.M., Mori A.E. \& Barros C.S.L. 2007. Raiva em equinos. Anais XIII Encontro Nacional de Patologia Veterinária, Campo Grande, MS, p.145-146. (Resumo)

Pimentel L.A., Oliveira D.M., Galiza G.J.N., Rego R.O., Dantas A.F.M. \& Riet-Correa F. 2009. Doenças do sistema nervoso central de equídeos no semi-árido. Pesq. Vet. Bras. 29:589-597.

Radostits O.M., Gay C.C. \& Hinchcliff K.W. 2002. Clínica Veterinária. $9^{\mathrm{a}}$ ed. Guanabara Koogan, Rio de Janeiro, p.1077-1083.

Rech R.R. 2007. Alterações no encéfalo de bovinos submetidos à vigilância das encefalopatias espongiformes transmissíveis. Tese de Doutorado, Universidade Federal de Santa Maria, Santa Maria. 228p.

Silva R.A., Silva N.M. \& Menezes P.R.V. 1974. Ocorrência do vírus da raiva na medula e no bulbo de eqüinos na doença natural e sua ausência nas diferentes regiões do sistema nervoso central e outros tecidos. Pesq. Agropec. Bras., Série Vet. 9:29-31.

Summers B.A., Cummings J.F. \& Lahunta A. 1995. Veterinary Neuropathology. Mosby, Baltimore, p.95-99.

Teixeira T.F., Holz C.L., Caixeta S.P.M.B., Dezen D., Cibulski S.P., Silva J.R., Rosa J.C.A., Schmidt E., Ferreira J.C., Batista H.B.C.R., Caldas E., Franco A.C. \& Roehe P.M. 2008. Diagnóstico de raiva no Rio Grande do Sul, Brasil, de 1985 a 2007. Pesq. Vet. Bras. 28:515520.

Tizard I.R. 1996. Vaccination and vaccines. Veterinary Immunology. W.B. Saunders, Philadelphia, p.265-284.

Zimmer K., Wiegand D., Manz D., Frost J.W., Reinacher M. \& Frese K. 1990. Evaluation of five different methods for routine diagnosis of rabies. J. Vet. Med. B 37:392-400. 